\title{
Feasibility of Carbonaceous Nanomaterial-Assisted Photocatalysts Calcined at Different Temperatures for Indoor Air Applications
}

\author{
Wan-Kuen Jo and Kun-Hwan Kim \\ Department of Environmental Engineering, Kyungpook National University, University Road, Bukgu, \\ Daegu 702-701, Republic of Korea \\ Correspondence should be addressed to Wan-Kuen Jo, wkjo@knu.ac.kr
}

Received 5 June 2012; Revised 2 July 2012; Accepted 16 July 2012

Academic Editor: Jiaguo Yu

Copyright $\odot 2012$ W.-K. Jo and K.-H. Kim. This is an open access article distributed under the Creative Commons Attribution License, which permits unrestricted use, distribution, and reproduction in any medium, provided the original work is properly cited.

This study examined the characteristics and photocatalytic activity of multiwall carbon nanotube-assisted $\mathrm{TiO}_{2}\left(\mathrm{MWNT}^{-\mathrm{TiO}}{ }_{2}\right)$ nanocomposites calcined at different temperatures to assess their potential indoor air applications. It was confirmed that the composites calcined at low temperatures $\left(300\right.$ and $\left.400^{\circ} \mathrm{C}\right)$ contained $\mathrm{TiO}_{2}$ nanoparticles bound intimately to the MWNT networks. Meanwhile, almost no MWNTs were observed when the calcination temperature was increased to 500 and $600^{\circ} \mathrm{C}$. The $\mathrm{MWNT}-\mathrm{TiO}_{2}$ composites calcined at low temperatures showed higher photocatalytic decomposition efficiencies for aromatic hydrocarbons at indoor concentrations than those calcined at high temperatures. The mean efficiencies for benzene, toluene, ethyl benzene, and o-xylene (BTEX) by the composite calcined at $300^{\circ} \mathrm{C}$ were $32,70,79$, and $79 \%$, respectively, whereas they were $33,71,78$, and $78 \%$ for the composite calcined at $400^{\circ} \mathrm{C}$, respectively. In contrast, the efficiencies decreased to close to zero when the calcination temperature was increased to $600^{\circ} \mathrm{C}$. Moreover, the $\mathrm{MWNT}^{-\mathrm{TiO}_{2}}$ exhibited superior photocatalytic performance for the decomposition efficiencies compared to $\mathrm{TiO}_{2}$ under conventional UV-lamp irradiations. Consequently, these carbonaceous nanomaterial-assisted photocatalysts can be applied effectively to indoor air applications depending upon the calcination temperature.

\section{Introduction}

The photocatalytic process using titanium dioxide $\left(\mathrm{TiO}_{2}\right)$ has become an attractive advanced oxidation technology for addressing a variety of environmental problems owing to its potential to oxidize a wide range of environmental pollutants and long-term thermodynamic stability under certain operating conditions $[1,2]$. However, the current bottleneck for $\mathrm{TiO}_{2}$ photocatalysis lies in its low quantum yield and low photodegradation efficiency. Therefore, a range of modifying methods were attempted to enhance the photocatalytic properties of $\mathrm{TiO}_{2}$ for the decomposition of several environmental pollutants. The methods include nonmetallic doping, metallic doping, cocatalysts, dye sensitization, and adsorbent assistance [3-8].
Among these methods, carbonaceous adsorbent-assisted photocatalysts have attracted considerable attention because of their superior performance. Initially, granular- and fibrous-type activated carbons (ACs) were used as $\mathrm{TiO}_{2}$ supporters for certain environmental applications [9-11]. Later, other types of carbonaceous nanomaterials (particularly carbon nanotubes (CNTs)) were suggested as alternative supporters of mainly $\mathrm{TiO}_{2}$ due to the combined effect of the electronic and adsorption properties [7, 12, 13]. CNTs are generally classified into multi- and single-wall carbon nanotubes (MWNTs and SWNTs). The unique electronic properties of CNTs can retard the electron-hole recombination time, thereby enhancing the photocatalytic performance of $\mathrm{TiO}_{2}[7,13]$. In addition, CNTs have the potential to provide reactive surface areas approaching those 
provided by ACs and to adsorb hydrophobic species, which are barely adsorbed by $\mathrm{TiO}_{2}$ nanoparticles [14]. Accordingly, many studies [15-19] applied MWNT- or SWNT-assisted $\mathrm{TiO}_{2}$ photocatalysts (MWNT- or SWNT-TiO 2 ) for the purification of environmental pollutants and reported these nanomaterials to have superior performance to that of standalone $\mathrm{TiO}_{2}$. Unlike other types of photocatalysts, there are few reports on the effects of the calcination temperature of CNT-assisted $\mathrm{TiO}_{2}$ photocatalysts on the gas-phase pollutant decomposition. In particular, the calcination temperature can be an important parameter associated with the photocatalytic activity for certain photocatalysts [20-24]. This suggests that the photocatalytic activity of CNT-assisted $\mathrm{TiO}_{2}$ nanomaterials can vary with the calcination temperature.

Accordingly, this study examined the characteristics and heterogeneous photocatalytic activity of MWNT-assisted $\mathrm{TiO}_{2}\left(\mathrm{MWNT}-\mathrm{TiO}_{2}\right.$ ) photocatalysts prepared at different calcination temperatures to assess the feasibility of their indoor air applications. Although SWNTs have a higher specific surface area, they are more expensive than MWNTs [25]. Therefore, this study used MWNTs as a cost-effective $\mathrm{TiO}_{2}$ assistant material. The target environmental pollutants included four organic vapors (benzene, toluene, ethyl benzene, and xylene (also known as BTEX)), which are toxic or potentially toxic to humans [26]. These compounds are an important class of pollutants found frequently at high concentrations in a range of indoor environments [27]. The characteristics of BTEX have prompted the development of control means to minimize the health impacts of indoor air exposure. For indoor air applications, the surveyed concentration of each compound was chosen to be within the indoor air concentration (IAC) range (<1 ppm) [27].

\section{Methods}

2.1. Synthesis Route and Properties of MWNT-Assisted Photocatalyst. The MWNT-TiO 2 nanomaterials were synthesized using a sol-gel method. For this method, $0.7 \mathrm{~g}$ of MWNT (95.9\%, Carbon Nano-material Technology) was added to $50 \mathrm{~mL}$ of ethanol (99.9\% Merck) and sonicated for $20 \mathrm{~min}$. Subsequently, $15.5 \mathrm{~mL}$ of tetrabutyl orthotitanate (TBOT, Sigma-Aldrich) was added to the MWNT-ethanol solution. This mixture was sonicated for $30 \mathrm{~min}$ to achieve better mixing and stirred vigorously for $30 \mathrm{~min}$. Afterwards, $4 \mathrm{~mL}$ of nitric acid (69 wt\%, Junsei) and $20 \mathrm{~mL}$ of deionized water were added to the solution to catalyze the hydrolysis and condensation. The resulting mixture was stirred vigorously until a homogeneous gel was formed. The gel was aged in air for $4 \mathrm{~d}$ at room temperature, crushed into fine powders, and dried at $80^{\circ} \mathrm{C}$ in an oven for $12 \mathrm{~h}$. The powders were calcined at $300,400,500$, or $600^{\circ} \mathrm{C}$ for $5 \mathrm{~h}$. The calcined $\mathrm{CNT}-\mathrm{TiO}_{2}$ powders were coated on the inner surface of the pyrex reactor, using the method reported by Xagas et al. [28].

Before the coating procedure, the as-prepared MWNT$\mathrm{TiO}_{2}$ powders were examined for their surface and morphological properties. X-ray diffraction (XRD) patterns were determined on a Rigaku D/max-2500 diffractometer with $\mathrm{Cu} \mathrm{K}_{\alpha}$ radiation operated at $40 \mathrm{kV}$ and $100 \mathrm{~mA}$. Thermal gravity analysis (TGA) was done using a TA Instrument SDT Q600 TG/DTA in order to determine the carbon content in the MWNT- $\mathrm{TiO}_{2}$ powders. The particle morphology was observed using a Hitachi S-4300\&EDX-350 FE-scanning electron microscope (SEM) at an acceleration voltage of $15 \mathrm{kV}$. X-ray photoelectron spectroscope (XPS) measurements were done using a Thermo VG Scientific Escalab 250 spectrometer with monochromatized Al Ka excitation. Fourier transform infrared (FTIR) analysis was performed on a PerkinElmer Spectrum GX spectrophotometer at a resolution of $4 \mathrm{~cm}^{-1}$ in the spectral range of $400-4,000 \mathrm{~cm}^{-1}$, using a KBR pellet for sample preparation.

\subsection{Application of MWNT-Assisted $\mathrm{TiO}_{2}$ Nanocomposites to} BTEX Decomposition. The experimental setup is illustrated in Figure 1. An annular-geometry reactor was used to evaluate the as-prepared $\mathrm{MWNT}-\mathrm{TiO}_{2}$ nanomaterials for the decomposition of gas-phase BTEX. The reactor consisted of a pyrex tube coated on the inner surface with a thin film of the MWNT-TiO 2 nanomaterials. A conventional cylindrical lamp or a hexahedral tube installed with lightemitting diodes (LEDs) was inserted inside another pyrex tube (outside diameter, $25 \mathrm{~mm}$ ), whose outer surface served as the inner surface of the annular reactor. The gas flowed through the annular region. This design was particularly suited for research, because it provided a well-characterized reactive catalyst surface along the length of the reactor body and allowed uniform light distribution. Moreover, the reactor was designed to direct the flow of incoming air toward the UV light to increase the air turbulence inside the reactor, thereby enhancing the distribution of target compounds onto the catalytic surface of the reactor. The humidity was adjusted by passing zero-grade air through a charcoal filter, followed by a humidification device in a water bath. The relative humidity $(\mathrm{RH})$ was measured in front of the photocatalytic reactor inlet using a humidity meter ( $\mathrm{T} \& \mathrm{D}$ Thermo Recorder TR-72S). The flow rate (FR) measurement was carried out using identical rotameters (0-10 $\left.\mathrm{L} \mathrm{min}^{-1}\right)$ calibrated to a dry test meter (URG 3000020C). The air stream was heated externally to help vaporize the BTEX injected into the mixing chamber through a syringe pump (Kd Scientific Model 210). The air stream was then finally fed to the photocatalytic reactor. The desired concentration of the standard gas was controlled by adjusting the FR and BTEX injection rate.

The major photocatalytic parameters were the input concentration (IC), RH, light source, FR, and hydraulic diameter (HD, which is defined as the inside diameter of the annular reactor tube minus the outside diameter of the lamp). The IC was fixed to $0.1 \mathrm{ppm}$ for each component of BTEX to simulate the IAC condition. The RH was adjusted to $50 \%$, which was within the American Society of Heating, Refrigerating and Air-Conditioning Engineers comfort range $(40-60 \%)$. UV radiation was supplied using a conventional 8-W fluorescent black light (Sankyo Denki F8T5/BLB) with a maximum spectral intensity at $352 \mathrm{~nm}$ or 42 0.06-W UV-LEDs (Moksan MS-L512UVP) with a maximum spectral intensity at $380 \mathrm{~nm}$. The FR was adjusted 


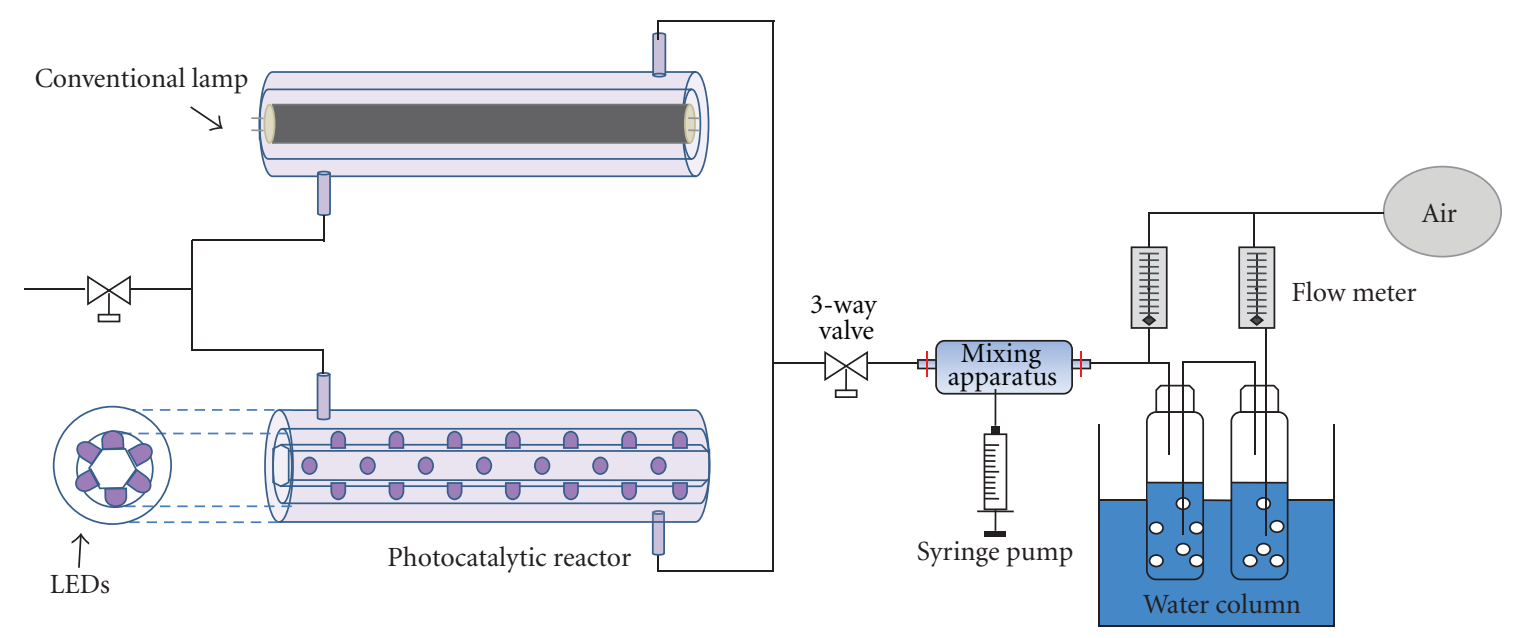

FIGURE 1: Schematic diagram of the experimental setup.

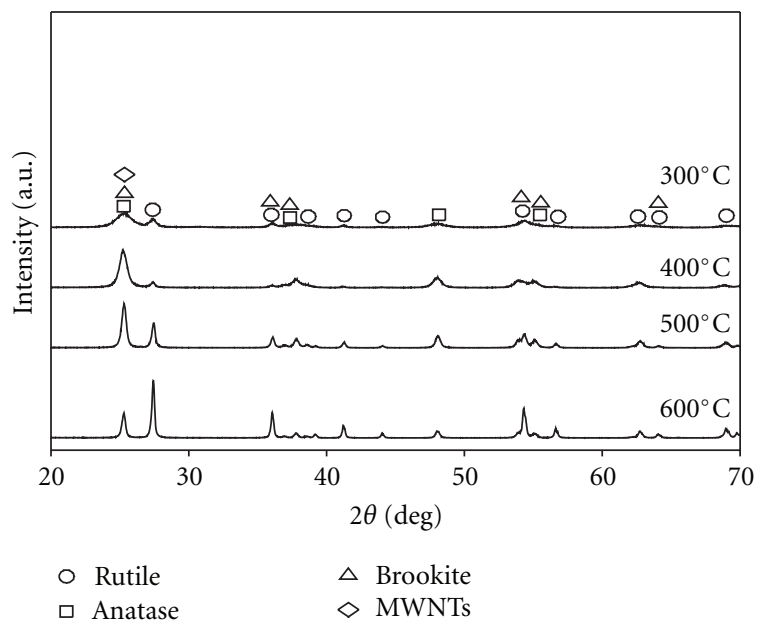

Figure 2: X-ray diffraction pattern of $\mathrm{MWNT}-\mathrm{TiO}_{2}$ at four different calcination temperatures $\left(300,400,500\right.$, and $\left.600^{\circ} \mathrm{C}\right)$.

to 1.0 or $4.0 \mathrm{~L} \mathrm{~min}^{-1}$, giving a residence time of 7.2 and $1.8 \mathrm{~s}$, respectively. The former FR was used to compare the decomposition efficiencies of the $\mathrm{MWNT}^{-\mathrm{TiO}_{2}}$ composites irradiated using the two light-source types. The latter FR was used to examine the effects of the calcination temperature on the photocatalytic decomposition efficiency of the nanocomposites. The HD of the reactor was $10 \mathrm{~mm}$.

Air measurements were performed by collecting air samples periodically at the inlet and outlet of the photocatalytic reactor and analyzing them by gas chromatography (GC, Hewlett-Packard 4890) or mass spectrometry (MS, Hewlett Packard MSD5973) coupled with a thermal desorption (TD, Donam TD-II) unit. Sampling was done by filling an evacuated Tedlar bag at a constant flow rate. The gas from this bag was then drawn through a $0.64 \mathrm{~cm}$ outside diameter and $18 \mathrm{~cm}$ long SS sorbent trap containing $0.4 \mathrm{~g}$ of Tenax TA using a constant flow-sampling pump (SKC Aircheck Sampler Model 224-PCXR8). The sampling time was varied from one to five min depending on the flow rate. All samples were taken at room temperature. The gaseous species collected on the sorbent trap were analyzed by TD/GC installed with a flame ionization detector or GC/MS. The quality control program involved an analysis of the laboratory blank traps and spiked samples. At the beginning of the day, a laboratory blank trap was analyzed for contamination but no trap contamination was identified. A spiked external standard was also analyzed daily to check the quantitative response. The method detection limits ranged from 0.3 to $0.5 \mathrm{ppb}$ for BTEX, depending on the compounds.

\section{Results and Discussion}

3.1. Properties of MWNT-Assisted $\mathrm{TiO}_{2}$ Nanocomposites according to Calcination Temperature. The characteristics of the MWNT-assisted nanomaterials prepared at different calcination temperatures were investigated using a range of optical and analytical instruments. Figure 2 exhibits the XRD patterns of the MWNT- $\mathrm{TiO}_{2}$ composites calcined at four different temperatures $\left(300,400,500\right.$, and $600^{\circ} \mathrm{C}$, for $\mathrm{MWNT}^{-\mathrm{TiO}_{2}-300,}$ MWNT-TiO $2-400, \mathrm{MWNT}_{2}-\mathrm{TiO}_{2}$ 500, and $\mathrm{MWNT}-\mathrm{TiO}_{2}-600$, resp.). The anatase content of the composites decreased with increasing calcination temperature and the rutile and brookite contents increased. This pattern is consistent with that reported by Wang et al. [15]. In addition, the peak at $25.3^{\circ} 2 \theta$ became broader with decreasing calcination temperature. The broad peaks obtained from both the MWNT- $\mathrm{TiO}_{2}-300$ and MWNT$\mathrm{TiO}_{2}-400$ were assigned to overlap of the peak at $26.0^{\circ} 2 \theta$, which was assigned to MWNTs [14], with the anatase peak at $25.3^{\circ} 2 \theta$ [29]. The sharp peaks at approximately $25.3^{\circ} 2 \theta$ for both $\mathrm{MWNT}-\mathrm{TiO}_{2}-500$ and $\mathrm{MWNT}^{-} \mathrm{TiO}_{2}-600$ were attributed to the low thermal stability of MWNTs [25]. MWNTs and certain unidentified chemical species might have been destroyed during the calcination processes under such high-temperature conditions. This assertion was supported by TGA (Figure 3), in that there were

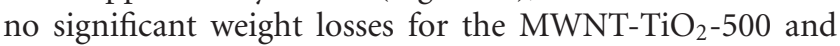
MWNT-TiO $2-600$. Consequently, $\mathrm{TiO}_{2}$ crystallites would be 


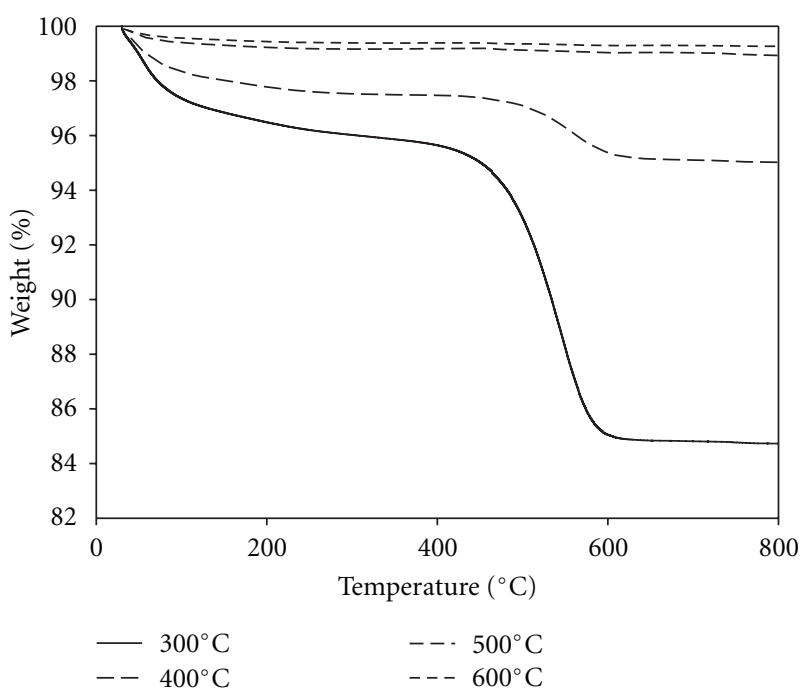

Figure 3: Thermogravimetric analysis of $\mathrm{MWNT}^{-\mathrm{TiO}_{2}}$ at four different calcination temperatures $\left(300,400,500\right.$, and $\left.600^{\circ} \mathrm{C}\right)$.

the major component of these composites, resulting in sharp peaks at approximately $25.3^{\circ} 2 \theta$.

Figure 3 also exhibits that for the MWNT-TiO $2-300$ and MWNT-TiO $2-400$, three-step weight losses were observed over the temperature range $20-800^{\circ} \mathrm{C}$. An endothermic weight loss was observed between 20 and $500^{\circ} \mathrm{C}$, which was attributed to the release of the residual $\mathrm{TiO}_{2}$ precursor and organic solvent. A second sharper weight loss (11 and

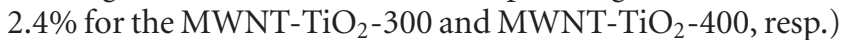
was observed between 500 and $600^{\circ} \mathrm{C}$ and attributed to the thermal decomposition of MWNTs and the crystallization of amorphous $\mathrm{TiO}_{2}$ [14]. On the other hand, almost no weight loss was observed between 630 and $800^{\circ} \mathrm{C}$, suggesting that $\mathrm{TiO}_{2}$ became the major component at this temperature range.

Unlike the MWNT-TiO $2-300$ and $\mathrm{MWNT}_{2} \mathrm{TiO}_{2}-400$, SEM images revealed almost no MWNTs in $\mathrm{MWNT}_{-} \mathrm{TiO}_{2}-$ 500 and $\mathrm{MWNT}-\mathrm{TiO}_{2}-600$ (Figure 4). This supports the assertion that MWNTs might have been destroyed during the calcination processes at high temperatures. In contrast, $\mathrm{TiO}_{2}$ nanoparticles in $\mathrm{MWNT}-\mathrm{TiO}_{2}-300$ and $\mathrm{MWNT}^{-T i O}{ }_{2}-$ 400 were bound intimately to the MWNT networks.

Figure 5 illustrates the XP spectra of the $\mathrm{C} 1 \mathrm{~s}$ regions for the MWNT- $\mathrm{TiO}_{2}$ composites calcined at four different

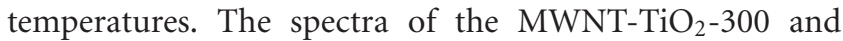
MWNT- $\mathrm{TiO}_{2}-400$ yielded four peaks at 283.6, 284.5, 286.3, and $288.8 \mathrm{eV}$, which were assigned to graphitic carbon atoms (46 and 35\% for MWNT-TiO -300 and $\mathrm{MWNT}-\mathrm{TiO}_{2}-400$, resp.), $-\mathrm{C}-\mathrm{O},-\mathrm{C}=\mathrm{O}$, and $-\mathrm{COO}$ bonds, respectively. The COO bond was likely formed by the oxidation of MWNT surfaces during the composite synthesis process [30]. On the other hand, for the MWNT-TiO -500 and MWNT$\mathrm{TiO}_{2}-600$, the corresponding peaks exhibited much lower intensities, were just trace, or were not shown. This again was attributed to the destruction of MWNTs and other chemical species during the calcination processes at these high temperatures.

Pure MWNT and MWNT-TiO 2 powders calcined at different temperatures revealed different FTIR spectra (Figure 6). For both the pure and calcined nanocomposites, the main absorption peaks were located at 3440 and $1626 \mathrm{~cm}^{-1}$, which were assigned to the $\mathrm{O}-\mathrm{H}$ stretching vibration of hydroxyl groups and the $\mathrm{O}-\mathrm{H}$ bending of surface adsorbed water, respectively [31]. For the calcined MWNT-TiO 2 powders, although their intensities differed according to the calcination temperature, other distinctive peaks were observed at low frequency bands $<1,000 \mathrm{~cm}^{-1}$. These peaks were assigned to the $\mathrm{Ti}-\mathrm{O}-\mathrm{Ti}$ vibration of the network [32], confirming the presence of $\mathrm{TiO}_{2}$ in the calcined nanocomposites.

3.2. BTEX Decomposition Efficiencies via $\mathrm{MWNT}_{-} \mathrm{TiO}_{2}$ Nanocomposites. The as-prepared $\mathrm{MWNT}-\mathrm{TiO}_{2}$ nanomaterials were evaluated for the decomposition of gas-phase BTEX at an IAC level $(0.1 \mathrm{ppm})$. Figure 7 illustrates the average photocatalytic decomposition efficiencies for BTEX determined using the $\mathrm{MWNT}-\mathrm{TiO}_{2}$ unit with two light sources (conventional 8-W black-light and blue LED lamps) under the FR condition of $1.0 \mathrm{~L} \mathrm{~min}^{-1}$. Under similar operating conditions, the decomposition efficiencies determined using the conventional lamp/MWNT- $\mathrm{TiO}_{2}$ unit were higher those of the conventional lamp/Degussa P25 $\mathrm{TiO}_{2}$ unit, which were reported previously [33]. The mean efficiencies obtained from the conventional lamp/MWNT- $\mathrm{TiO}_{2}$ unit were $95 \%$ for benzene and $\sim 100 \%$ for the other target compounds (TEX). Jo and Yang [33] reported the mean degradation efficiencies for BTEX obtained from the conventional lamp/Degussa $\mathrm{P} 25 \mathrm{TiO}_{2}$ unit of 56\%, 76\%, 92\%, and $93 \%$, respectively. Consequently, the $\mathrm{MWNT}^{-\mathrm{TiO}_{2}} \mathrm{com}-$ posite revealed superior performance in the photocatalytic decompositions of IAC-level toxic aromatic pollutants to the commercially available reference photocatalyst, Degussa $\mathrm{P} 25 \mathrm{TiO}_{2}$. This was attributed to the combined electrical properties and adsorption capacity of the $\mathrm{MWNT}^{-\mathrm{TiO}_{2}}$ composite. MWNTs have a large electron-storage capacity to store photon-excited electrons in $\mathrm{MWNT}^{-\mathrm{TiO}_{2}}$ nanomaterials [25]. This electron-storage capacity would likely retard or hinder electron-hole recombination. In addition, at the interface of $\mathrm{MWNT}^{-\mathrm{TiO}_{2}}$, electrons transfer from the $\mathrm{TiO}_{2}$ with a higher than Fermi energy level to the MWNT with a lower Fermi energy level to adjust the Fermi energy levels [13]. This electron transfer can result in $\mathrm{TiO}_{2}$ with an excess negative charge and MWNT with an excess positive charge. Thus, the MWNT would act as an electron sink. Consequently, the formation of this MWNT-TiO 2 junction would extend the recombination times of the photogenerated electron-hole pairs, thereby enhancing the photocatalytic activity of $\mathrm{TiO}_{2}$. MWNTs also have high adsorption capacity with typical specific surface areas of $200-400 \mathrm{~m}^{2} \mathrm{~g}^{-1}$ [25]. Therefore, MWNTs would assist the $\mathrm{TiO}_{2}$ powders by concentrating the pollutants and intermediates around the powders followed by subsequent migration of these species to the surface of the photocatalyst 


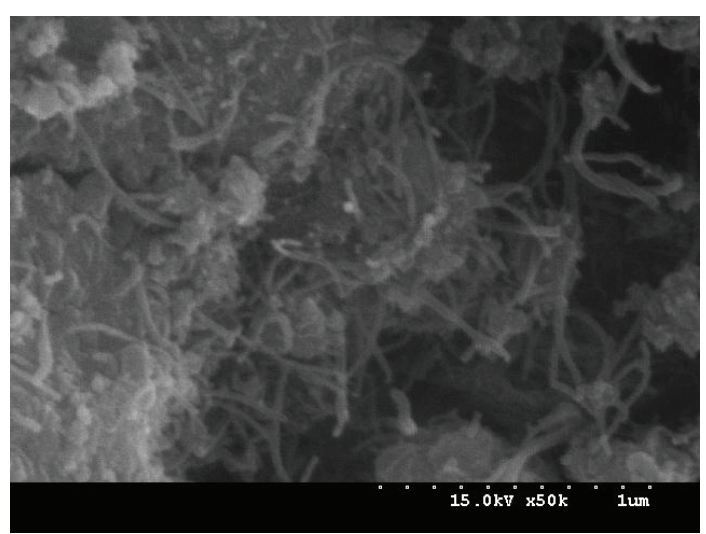

(a)

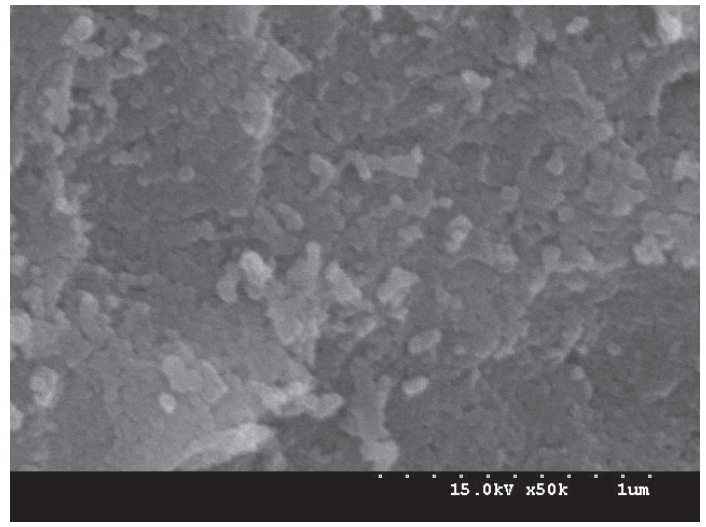

(c)

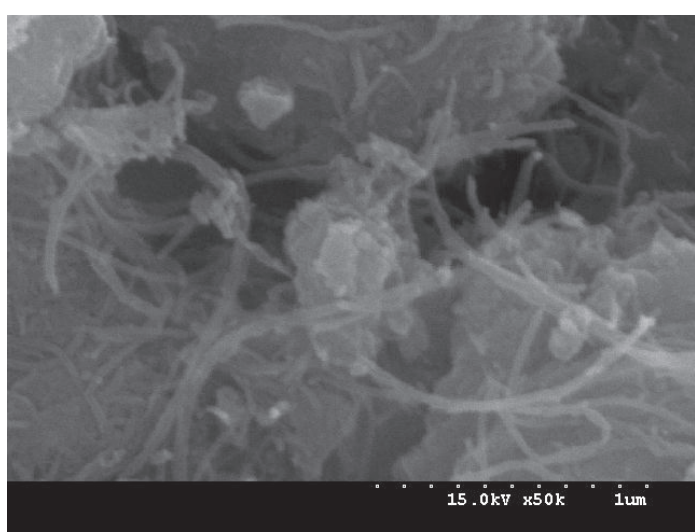

(b)

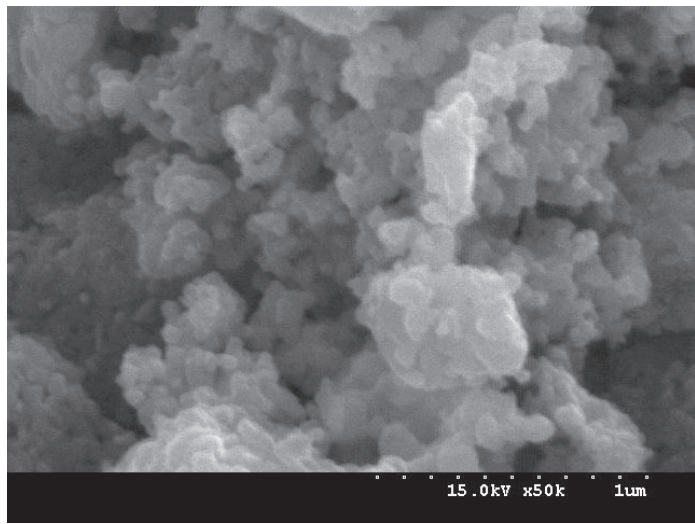

(d)

FIgURE 4: Scanning electron microscopy images of $\mathrm{MWNT}^{-\mathrm{TiO}_{2}}$ at four different calcination temperatures $\left(300,400,500\right.$, and $\left.600^{\circ} \mathrm{C}\right)$.

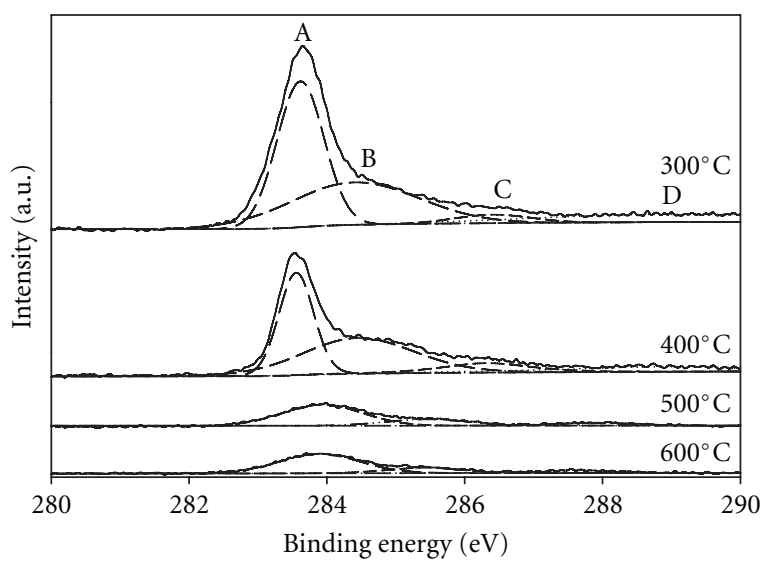
(A) Graphite carbon
(C) $\mathrm{C}=\mathrm{O}$
(B) $\mathrm{C}-\mathrm{O}$
(D) $\mathrm{COO}$

Figure 5: X-ray photoelectron spectra of $\mathrm{MWNT}^{-\mathrm{TiO}_{2}}$ at four different calcination temperatures $\left(300,400,500\right.$, and $\left.600^{\circ} \mathrm{C}\right)$.

via diffusion [34]. Adsorption in MWNTs would occur in the aggregated pores, inside the tube, or on the external walls [25].

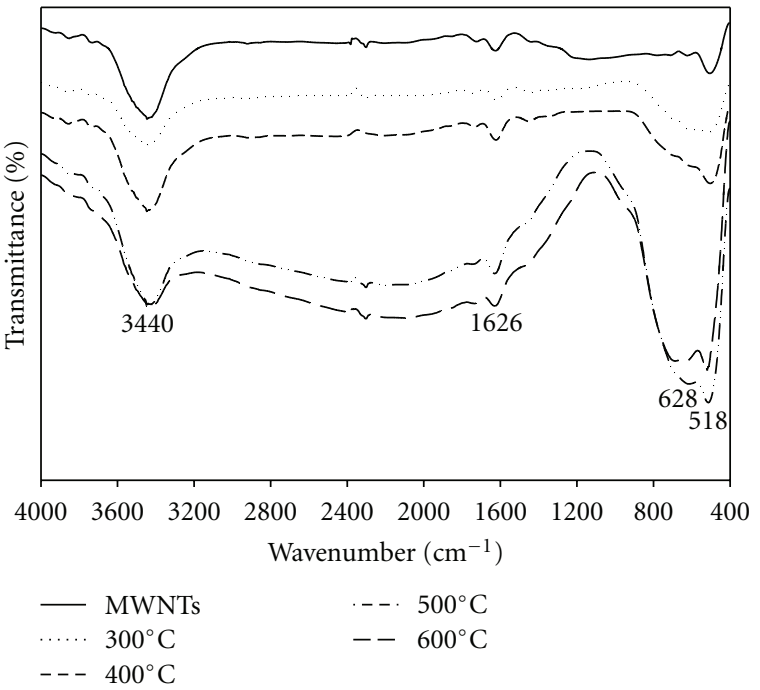

FIGURE 6: Fourier transform infrared spectra of $\mathrm{MWNT}^{-\mathrm{TiO}_{2}}$ at four different calcination temperatures $\left(300,400,500\right.$, and $\left.600^{\circ} \mathrm{C}\right)$.

Figure 7 compares the decomposition performance of the MWNT- $\mathrm{TiO}_{2}$ units using the conventional lamp with that using the blue LEDs. The decomposition efficiencies 


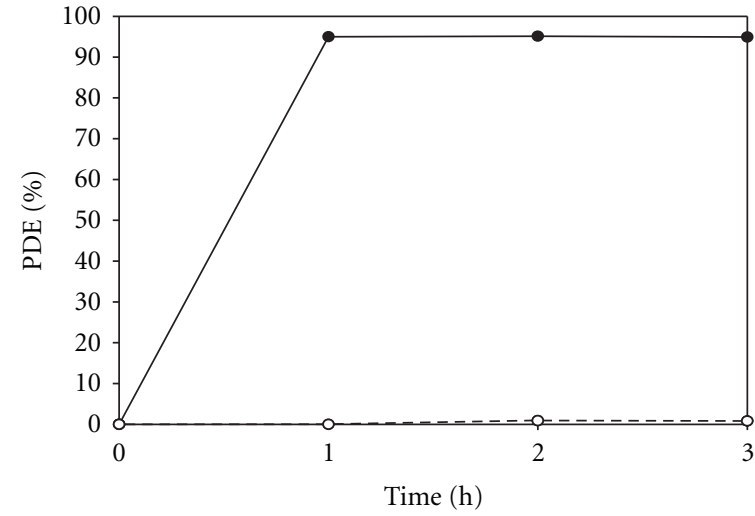

(a)

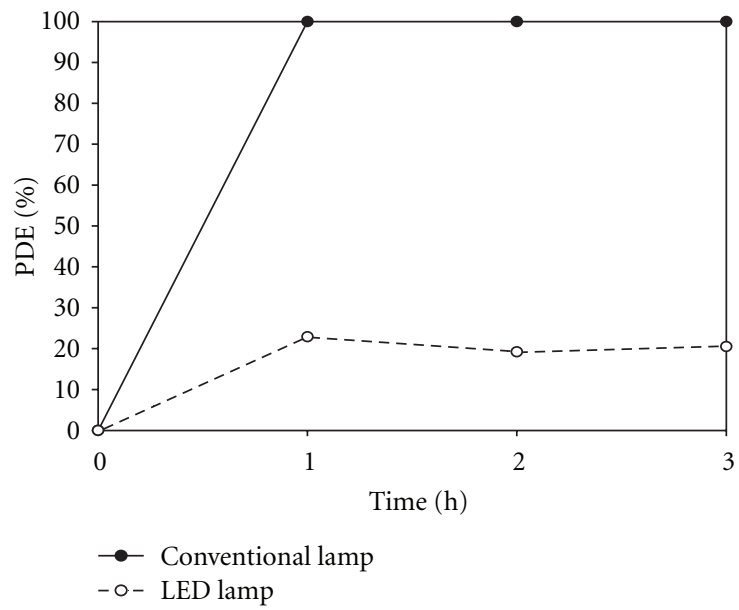

(c)

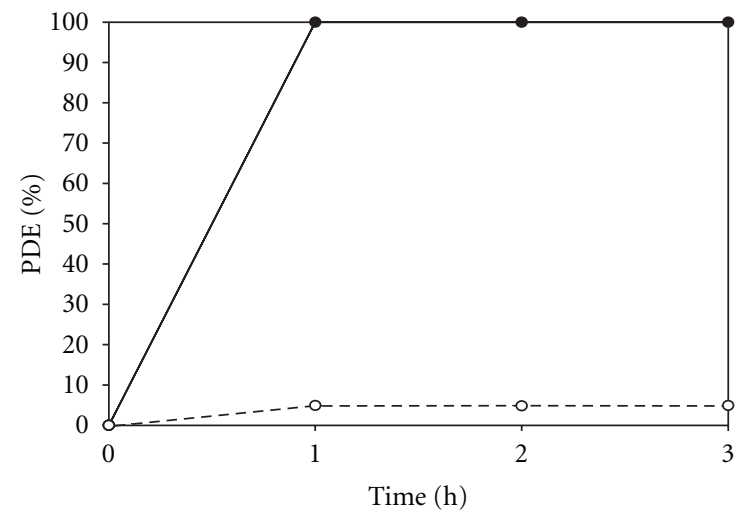

(b)

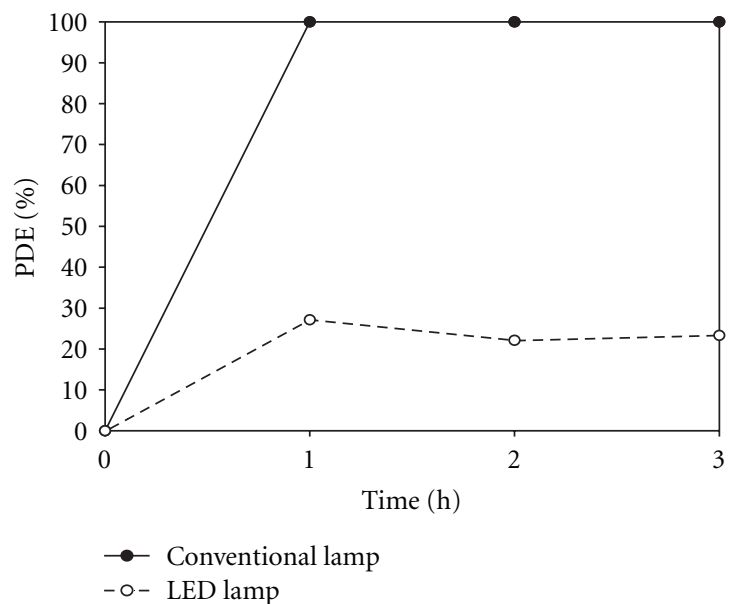

(d)

Figure 7: Time-series photocatalytic decomposition efficiencies determined via $\mathrm{MWNT}^{-\mathrm{TiO}_{2}}$ irradiated using two light-source types (conventional 8-W black light lamp and blue-LEDs): benzene (a), toluene (b), ethyl benzene (c), and o-xylene (d).

for BTEX determined using the conventional lamp/MWNT$\mathrm{TiO}_{2}$ unit were higher than those of the blue LEDs/MWNT$\mathrm{TiO}_{2}$ unit. For the blue-LED/MWNT-TiO 2 unit, the average efficiencies for BTEX were approximately zero, 5, 23, and $28 \%$, respectively. $\mathrm{TiO}_{2}$ is a semiconductor photocatalyst with a band gap energy of $3.2 \mathrm{eV}$, meaning that only light with a wavelength $\leq 385 \mathrm{~nm}$ can overcome this barrier [35]. Since the conventional lamp and UV-LED exhibit the maximum light intensity at 352 and $380 \mathrm{~nm}$, respectively, both light sources had sufficient energy to promote electrons from the valence band to the conduction band of $\mathrm{TiO}_{2}$. In general, the activity of the photocatalyst depends strongly on the photon flux on the surface of the catalyst as well as the light irradiation (energy per unit area) [36, 37]. In the present study, the conventional lamp revealed higher light intensity $\left(3.4 \mathrm{~mW} \mathrm{~cm}^{-2}\right)$ than that of the UVLED $\left(0.6 \mathrm{~mW} \mathrm{~cm}^{-2}\right)$. Therefore, the higher decomposition efficiency for the conventional lamp/MWNT- $-\mathrm{TiO}_{2}$ unit was attributed to the combined effects of the lower wavelength (higher energy) with higher light intensity.
Different calcination temperatures might yield different photocatalytic behaviors due to different morphological and electronic properties of $\mathrm{MWNT}-\mathrm{TiO}_{2}$ nanomaterials. Figure 8 represents the decomposition efficiencies as a function of the calcination temperature under the conditions of $\mathrm{FR}=4.0 \mathrm{~L} \mathrm{~min}^{-1}$ and conventional UV lamp irradiation. For the target compounds, $\mathrm{MWNT}-\mathrm{TiO}_{2}-300$ and $\mathrm{MWNT}-\mathrm{TiO}_{2}$ 400 showed similar decomposition efficiency. The mean efficiencies for BTEX by the MWNT- $\mathrm{TiO}_{2}-300$ were 32, 70, 79 , and $79 \%$, respectively, whereas they were $33,71,78$, and $78 \%$ for the MWNT- $\mathrm{TiO}_{2}-400$, respectively. On the other hand, when the calcination temperature was increased to $500^{\circ} \mathrm{C}$, the decomposition efficiencies decreased to close to zero for both benzene and toluene and to 42 and $44 \%$ for ethyl benzene and o-xylene, respectively. When the temperature was increased to $600^{\circ} \mathrm{C}$, the decomposition efficiencies were all approximately zero. Higher photocatalytic activities obtained from the MWNT-TiO -300 and $\mathrm{MWNT}_{2}-\mathrm{TiO}_{2}-400$ were attributed to the combined effects of MWNTs and $\mathrm{TiO}_{2}$ nanoparticles bound intimately to the MWNT networks, as 


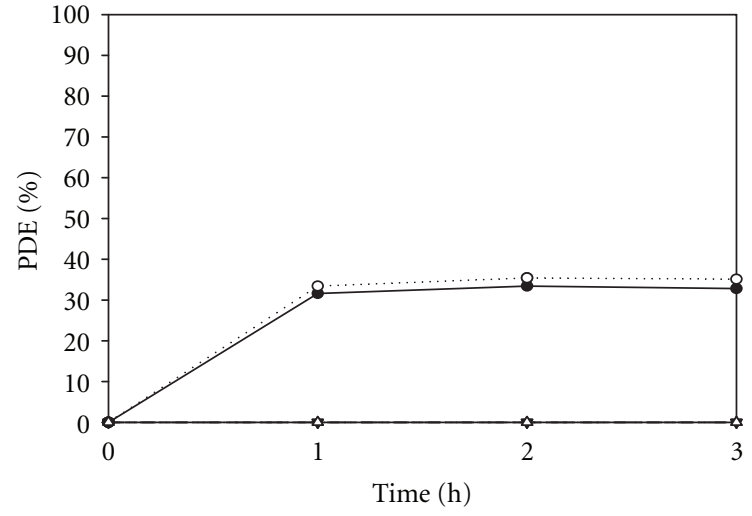

(a)

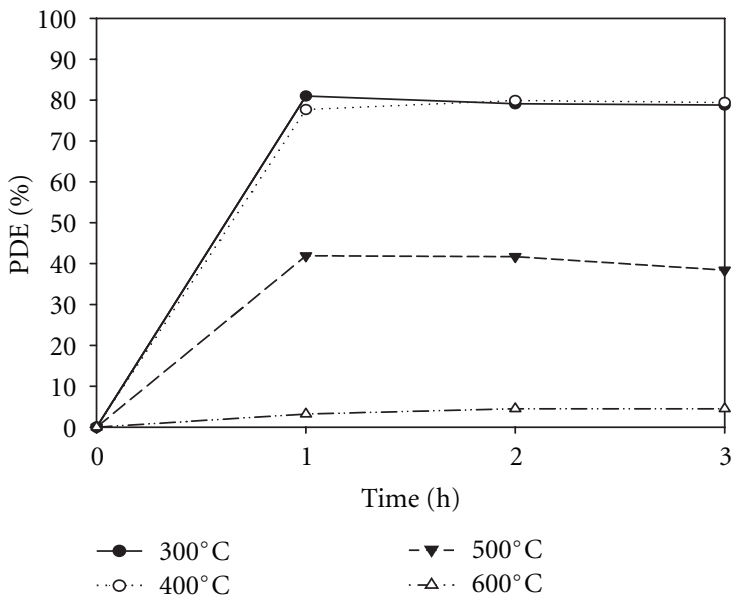

(c)

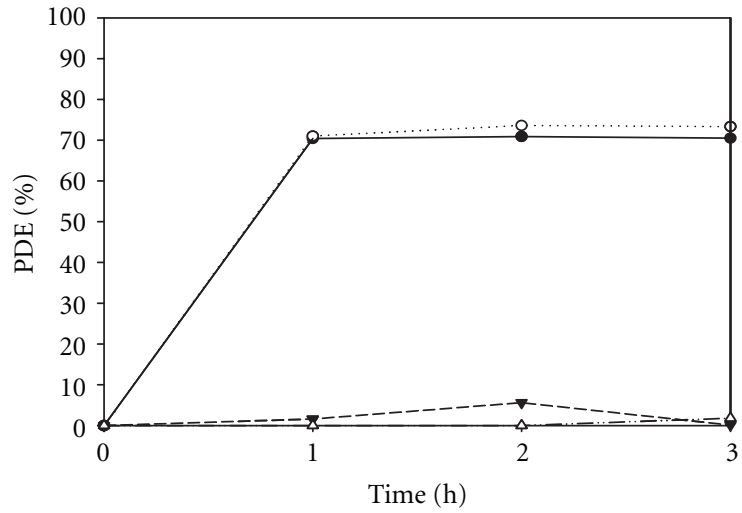

(b)

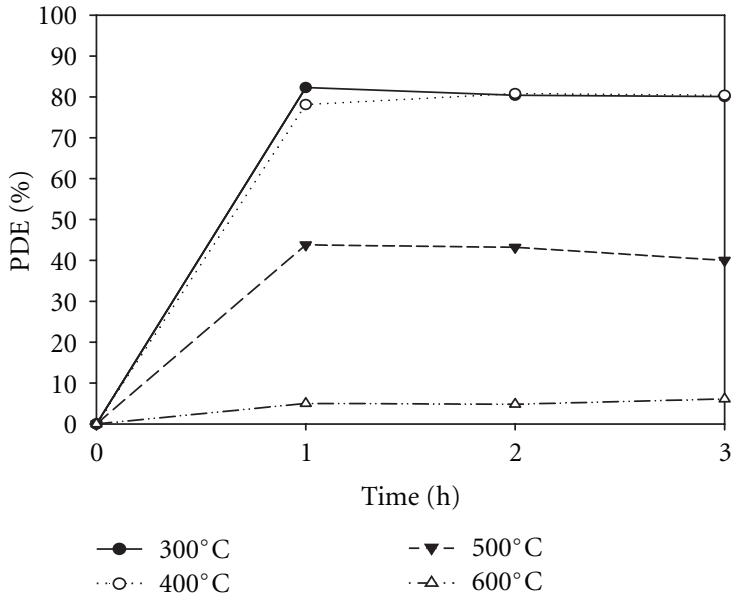

(d)

FIgURE 8: Time-series photocatalytic decomposition efficiencies (PDEs) determined via $\mathrm{MWNT}^{-T i O_{2}}$ according to the calcination temperatures: benzene (a), toluene (b), ethyl benzene (c), and o-xylene (d).

confirmed by the morphological and optical properties of the photocatalysts. This assertion is supported by that the carbon materials can accept photogenerated electrons and separate efficiently the charge carriers, thereby enhancing the photocatalytic activity [38-40].

\section{Conclusions}

This study investigated the feasibility of carbonaceous nanomaterial-assisted photocatalysts calcined at different temperatures for indoor air applications. The MWNT$\mathrm{TiO}_{2}$ composites calcined at different temperatures revealed different photocatalytic activities, morphologies, and surface properties. The optical and analytical results showed that for the composites calcined at low temperatures $\left(\leq 400^{\circ} \mathrm{C}\right)$ $\mathrm{TiO}_{2}$ nanoparticles were bound intimately to the MWNT networks. However, no MWNTs were observed when the calcination temperature was increased to higher values. Consistently, the MWNT- $\mathrm{TiO}_{2}$ composites calcined at the low temperatures showed higher photocatalytic decomposition efficiencies for aromatic hydrocarbons at IAC levels than those calcined at high temperatures. Moreover, MWNT$\mathrm{TiO}_{2}$ exhibited superior photocatalytic performance for the decomposition efficiencies to Degussa P25 $\mathrm{TiO}_{2}$ under conventional UV lamp irradiations, which was attributed to the combined electrical properties and adsorption capacity for the MWNT- $\mathrm{TiO}_{2}$ composite. Overall, these carbonaceous nanomaterial-assisted photocatalysts can be applied effectively to indoor air applications, depending on the calcination temperature.

\section{Acknowledgment}

This work was supported by the National Research Foundation of Korea (NRF) grant funded by the Korea government (MEST) (no. 2011-0027916).

\section{References}

[1] Y. Lu, D. Wang, Y. Wu, C. Ma, X. Zhang, and C. Yang, "Synergistic effect of nanophotocatalysis and nonthermal plasma on the removal of indoor HCHO," International Journal of Photoenergy, vol. 2012, Article ID 354032, 8 pages, 2012. 
[2] G. Wang, L. Xu, J. Zhang, T. Yin, and D. Han, "Enhanced photocatalytic activity of $\mathrm{TiO}_{2}$ powders (P25) via calcination treatment," International Journal of Photoenergy, vol. 2012, Article ID 265760, 9 pages, 2012.

[3] G. Wang, B. Cheng, J. Zhang, L. Xu, and T. Yin, "Facile synthesis and photocatalytic property of titania/carbon composite hollow microspheres with bimodal mesoporous shells," International Journal of Photoenergy, vol. 2012, Article ID 976389, 9 pages, 2012.

[4] W. K. Jo and J. T. Kim, "Application of visible-light photocatalysis with nitrogen-doped or unmodified titanium dioxide for control of indoor-level volatile organic compounds," Journal of Hazardous Materials, vol. 164, no. 1, pp. 360-366, 2009.

[5] R. Vinu, S. Polisetti, and G. Madras, "Dye sensitized visible light degradation of phenolic compounds," Chemical Engineering Journal, vol. 165, no. 3, pp. 784-797, 2010.

[6] G. Yang, Z. Jiang, H. Shi et al., "Study on the photocatalysis of F-S co-doped $\mathrm{TiO}_{2}$ prepared using solvothermal method," Applied Catalysis B, vol. 96, no. 3-4, pp. 458-465, 2010.

[7] R. Leary and A. Westwood, "Carbonaceous nanomaterials for the enhancement of $\mathrm{TiO}_{2}$ photocatalysis," Carbon, vol. 49, no. 3, pp. 741-772, 2011.

[8] G. Veréb, Z. Ambrus, Z. Pap et al., "Comparative study on $\mathrm{UV}$ and visible light sensitive bare and doped titanium dioxide photocatalysts for the decomposition of environmental pollutants in water," Applied Catalysis A, vol. 417-418, pp. 26-36, 2012.

[9] W. Zhou, P. Zhang, and W. Liu, "Anatase $\mathrm{TiO}_{2}$ nanospindle/activated carbon (ac) composite photocatalysts with enhanced activity in removal of organic contaminant," International Journal of Photoenergy, vol. 2012, Article ID 325902, 7 pages, 2012.

[10] S. Liu and X. Chen, "Preparation and characterization of a novel activated carbon-supported $\mathrm{N}$-doped visible light response photocatalyst $\left(\mathrm{TiO}_{2-}{ }_{x} \mathrm{Ny} / \mathrm{AC}\right)$, J Journal of Chemical Technology and Biotechnology, vol. 82, no. 5, pp. 453-459, 2007.

[11] S.-Y. Ye, Q. M. Tian, X.-L. Song, and S.-C. Luo, "Photoelectrocatalytic degradation of ethylene by a combination of $\mathrm{TiO}_{2}$ and activated carbon felts," Journal of Photochemistry and Photobiology A, vol. 208, no. 1, pp. 27-35, 2010.

[12] B. Ahmmad, Y. Kusumoto, S. Somekawa, and M. Ikeda, "Carbon nanotubes synergistically enhance photocatalytic activity of $\mathrm{TiO}_{2}$," Catalysis Communications, vol. 9, no. 6, pp. 1410-1413, 2008.

[13] K. Woan, G. Pyrgiotakis, and W. Sigmund, "Photocatalytic carbon-nanotube- $\mathrm{TiO}_{2}$ composites," Advanced Materials, vol. 21, no. 21, pp. 2233-2239, 2009.

[14] Q. Wang, D. Yang, D. Chen, Y. Wang, and Z. Jiang, "Synthesis of anatase titania-carbon nanotubes nanocomposites with enhanced photocatalytic activity through a nanocoatinghydrothermal process," Journal of Nanoparticle Research, vol. 9, no. 6, pp. 1087-1096, 2007.

[15] W. Wang, P. Serp, P. Kalck, and J. L. Faria, "Visible light photodegradation of phenol on $\mathrm{MWNT}-\mathrm{TiO}_{2}$ composite catalysts prepared by a modified sol-gel method," Journal of Molecular Catalysis A, vol. 235, no. 1-2, pp. 194-199, 2005.

[16] G. Hu, X. Meng, X. Feng, Y. Ding, S. Zhang, and M. Yang, "Anatase $\mathrm{TiO}_{2}$ nanoparticles/carbon nanotubes nanofibers: preparation, characterization and photocatalytic properties," Journal of Materials Science, vol. 42, no. 17, pp. 7162-7170, 2007.

[17] Y. Yao, G. Li, S. Ciston, R. M. Lueptow, and K. A. Gray, "Photoreactive $\mathrm{TiO}_{2}$ /carbon nanotube composites: synthesis and reactivity," Environmental Science and Technology, vol. 42, no. 13, pp. 4952-4957, 2008.

[18] C.-Y. Kuo, "Prevenient dye-degradation mechanisms using $\mathrm{UV} / \mathrm{TiO}_{2}$ /carbon nanotubes process," Journal of Hazardous Materials, vol. 163, no. 1, pp. 239-244, 2009.

[19] W.-C. Oh, A.-R. Jung, and W.-B. Ko, "Characterization and relative photonic efficiencies of a new nanocarbon/ $/ \mathrm{TiO}_{2} \mathrm{com}$ posite photocatalyst designed for organic dye decomposition and bactericidal activity," Materials Science and Engineering $C$, vol. 29, no. 4, pp. 1338-1347, 2009.

[20] T. Matsumoto, N. Iyi, Y. Kaneko et al., "High visible-light photocatalytic activity of nitrogen-doped titania prepared from layered titania/isostearate nanocomposite," Catalysis Today, vol. 120, no. 2, pp. 226-232, 2007.

[21] K. Suriye, P. Praserthdam, and B. Jongsomjit, "Control of $\mathrm{Ti}^{3+}$ surface defect on $\mathrm{TiO}_{2}$ nanocrystal using various calcination atmospheres as the first step for surface defect creation and its application in photocatalysis," Applied Surface Science, vol. 253, no. 8, pp. 3849-3855, 2007.

[22] M. A. Aramendía, V. Borau, J. C. Colmenares et al., "Modification of the photocatalytic activity of $\mathrm{Pd} / \mathrm{TiO}_{2}$ and $\mathrm{Zn} / \mathrm{TiO}_{2}$ systems through different oxidative and reductive calcination treatments," Applied Catalysis B, vol. 80, no. 1-2, pp. 88-97, 2008.

[23] A. Zaleska, E. Grabowska, J. W. Sobczak, M. Gazda, and J. Hupka, "Photocatalytic activity of boron-modified $\mathrm{TiO}_{2}$ under visible light: the effect of boron content, calcination temperature and $\mathrm{TiO}_{2}$ matrix," Applied Catalysis B, vol. 89, no. 3-4, pp. 469-475, 2009.

[24] A. Jia, X. Liang, Z. Su, T. Zhu, and S. Liu, "Synthesis and the effect of calcination temperature on the physical-chemical properties and photocatalytic activities of Ni,La codoped SrTiO3," Journal of Hazardous Materials, vol. 178, no. 1-3, pp. 233-242, 2010.

[25] P. Serp, M. Corrias, and P. Kalck, "Carbon nanotubes and nanofibers in catalysis," Applied Catalysis A, vol. 253, no. 2, pp. 337-358, 2003.

[26] C. S. Chen, Y. C. Hseu, S. H. Liang, J. Y. Kuo, and S. C. Chen, "Assessment of genotoxicity of methyl-tert-butyl ether, benzene, toluene, ethylbenzene, and xylene to human lymphocytes using comet assay," Journal of Hazardous Materials, vol. 153, no. 1-2, pp. 351-356, 2008.

[27] U. Schlink, A. Thiem, T. Kohajda, M. Richter, and K. Strebel, "Quantile regression of indoor air concentrations of volatile organic compounds (VOC)," Science of the Total Environment, vol. 408, no. 18, pp. 3840-3851, 2010.

[28] A. P. Xagas, E. Androulaki, A. Hiskia, and P. Falaras, "Preparation, fractal surface morphology and photocatalytic properties of $\mathrm{TiO}_{2}$ films," Thin Solid Films, vol. 357, no. 2, pp. 173-178, 1999.

[29] W. K. Jo and J. T. Kim, "Decomposition of gas-phase aromatic hydrocarbons by applying an annular-type reactor coatedwith sulfur-doped photocatalyst under visible-light irradiation," Journal of Chemical Technology and Biotechnology, vol. 85, no. 4, pp. 485-492, 2010.

[30] C. Y. Yen, Y. F. Lin, C. H. Hung et al., "The effects of synthesis procedures on the morphology and photocatalytic activity of multi-walled carbon nanotubes/ $/ \mathrm{TiO}_{2}$ nanocomposites," Nanotechnology, vol. 19, no. 4, Article ID 045604, 2008.

[31] K. Dai, T. Peng, D. Ke, and B. Wei, "Photocatalytic hydrogen generation using a nanocomposite of multi-walled carbon 
nanotubes and $\mathrm{TiO}_{2}$ nanoparticles under visible light irradiation," Nanotechnology, vol. 20, no. 12, Article ID 125603, 2009.

[32] T. Peng, D. Zhao, K. Dai, W. Shi, and K. Hirao, "Synthesis of titanium dioxide nanoparticles with mesoporous anatase wall and high photocatalytic activity," Journal of Physical Chemistry $B$, vol. 109, no. 11, pp. 4947-4952, 2005.

[33] W. K. Jo and C. H. Yang, "Feasibility of a tandem photocatalytic oxidation-adsorption system for removal of monoaromatic compounds at concentrations in the sub-ppm-range," Chemosphere, vol. 77, no. 2, pp. 236-241, 2009.

[34] A. Y. Shan, T. I. M. Ghazi, and S. A. Rashid, "Immobilisation of titanium dioxide onto supporting materials in heterogeneous photocatalysis: a review," Applied Catalysis A, vol. 389, no. 1-2, pp. 1-8, 2010.

[35] U. I. Gaya and A. H. Abdullah, "Heterogeneous photocatalytic degradation of organic contaminants over titanium dioxide: a review of fundamentals, progress and problems," Journal of Photochemistry and Photobiology C, vol. 9, no. 1, pp. 1-12, 2008.

[36] W. Wang and Y. Ku, "Photocatalytic degradation of gaseous benzene in air streams by using an optical fiber photoreactor," Journal of Photochemistry and Photobiology A, vol. 159, no. 1, pp. 47-59, 2003.

[37] T. H. Lim and S. D. Kim, "Trichloroethylene degradation by photocatalysis in annular flow and annulus fluidized bed photoreactors," Chemosphere, vol. 54, no. 3, pp. 305-312, 2004.

[38] J. Yu, T. Ma, and S. Liu, "Enhanced photocatalytic activity of mesoporous $\mathrm{TiO}_{2}$ aggregates by embedding carbon nanotubes as electron-transfer channel," Physical Chemistry Chemical Physics, vol. 13, no. 8, pp. 3491-3501, 2011.

[39] Q. Xiang, J. Yu, and M. Jaroniec, "Synergetic effect of $\mathrm{MoS}_{2}$ and graphene as cocatalysts for enhanced photocatalytic $\mathrm{H}_{2}$ production activity of $\mathrm{TiO}_{2}$ nanoparticles," Journal of the American Chemical Society, vol. 134, pp. 6575-6578, 2012.

[40] J. Yu, B. Yang, and B. Cheng, "Noble-metal-free carbon nanotube- $\mathrm{Cd}_{0.1} \mathrm{Zn}_{0.9} \mathrm{~S}$ composites for high visible-light photocatalytic $\mathrm{H}_{2}$-production performance," Nanoscale, vol. 4, pp. 2670-2677, 2012. 


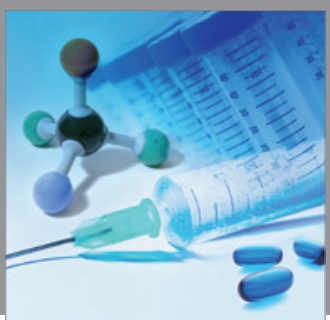

International Journal of

Medicinal Chemistry

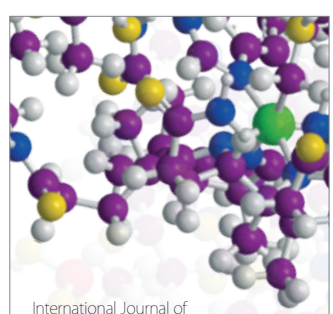

Carbohydrate Chemistry

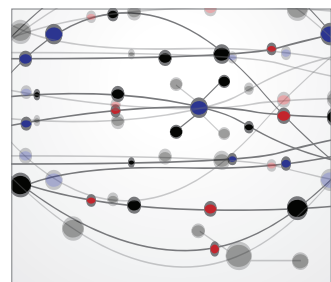

The Scientific World Journal
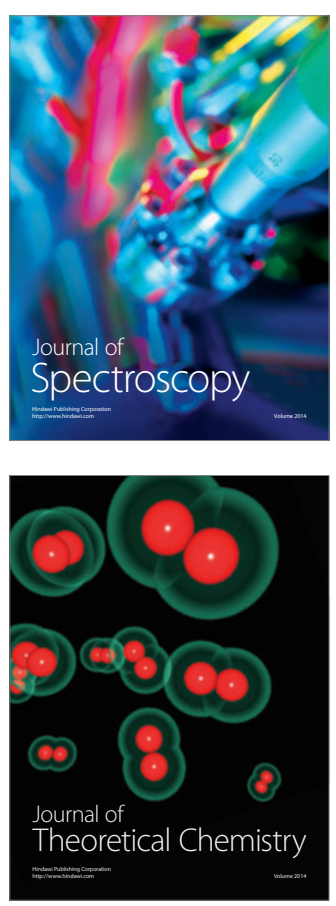
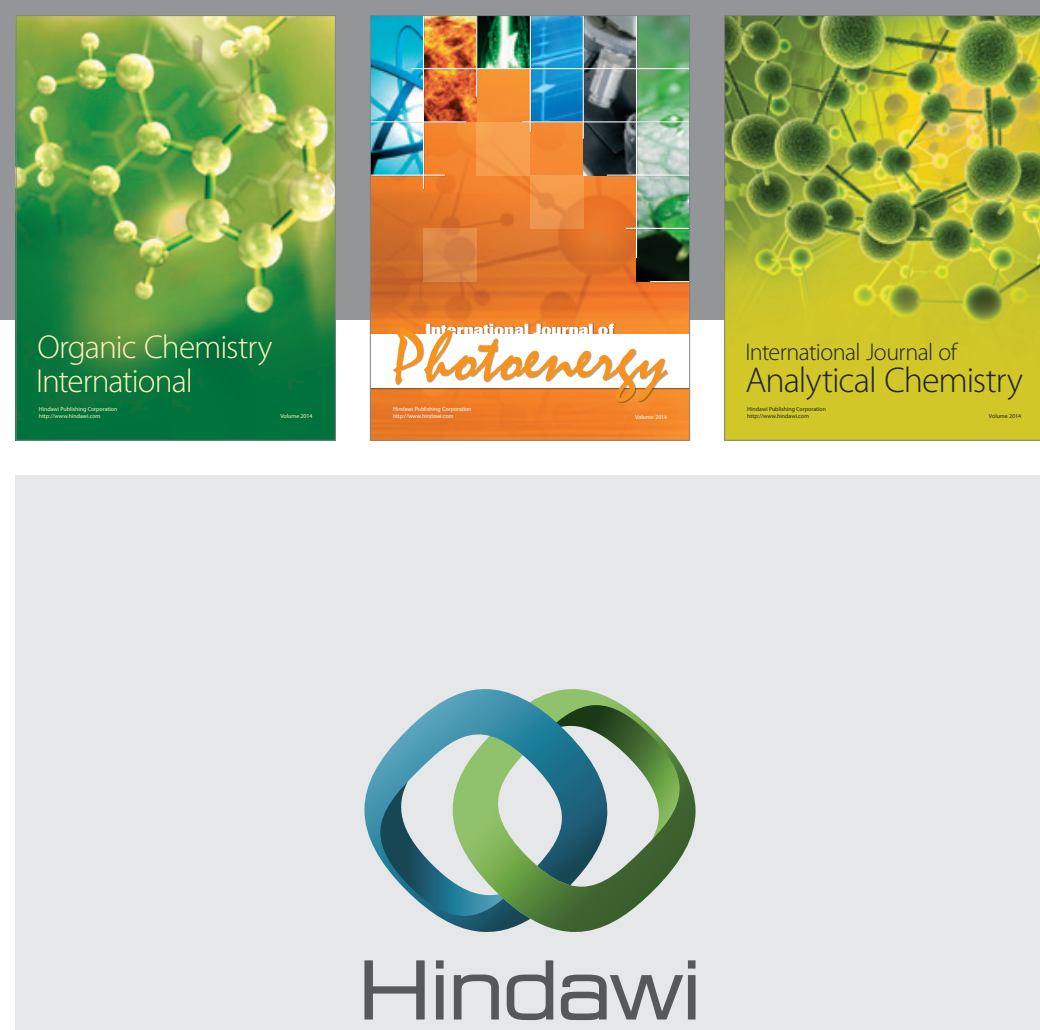

Submit your manuscripts at

http://www.hindawi.com
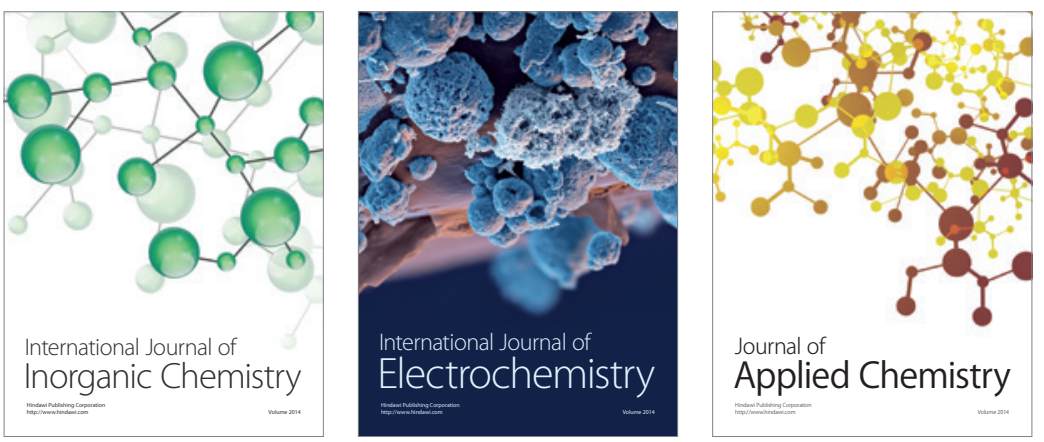

Journal of

Applied Chemistry
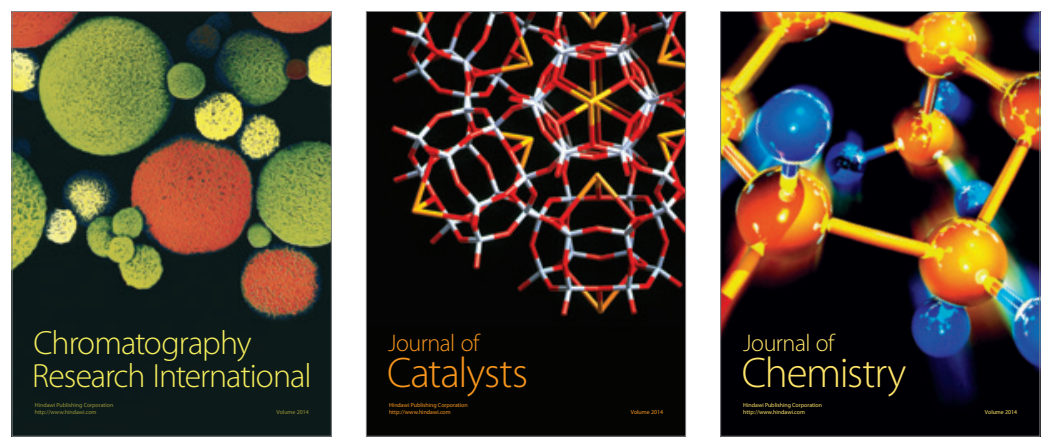
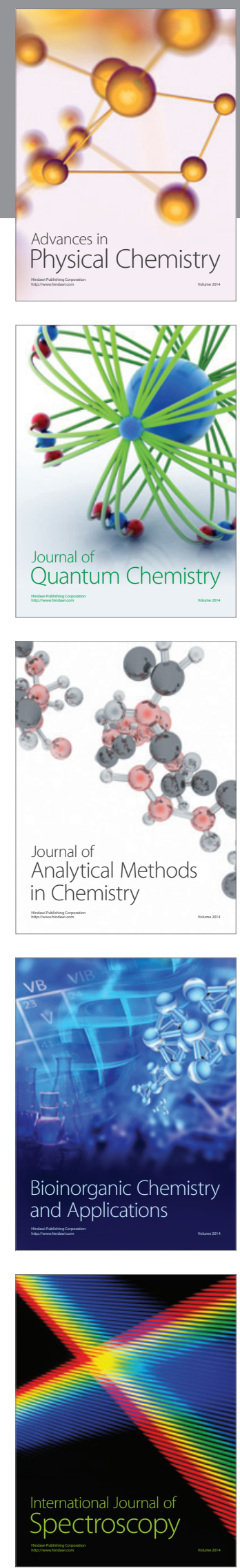